\title{
Lactic acid fermentation as a tool to enhance the antioxidant properties of Myrtus communis berries
}

\author{
José Antonio Curiel', Daniela Pinto ${ }^{2}$, Barbara Marzani², Pasquale Filannino ${ }^{1}$, Giovanni Antonio Farris ${ }^{3}$, \\ Marco Gobbetti ${ }^{1}$ and Carlo Giuseppe Rizzello ${ }^{1^{*}}$
}

\begin{abstract}
Background: Myrtle (Myrtus communis L.) is a medicinal and aromatic plant belonging to Myrtaceae family, which is largely diffused in the Mediterranean areas and mainly cultivated in Tunisia and Italy. To the best of our knowledge, no studies have already considered the use of the lactic acid fermentation to enhance the functional features of $M$. communis. This study aimed at using a selected lactic acid bacterium for increasing the antioxidant features of myrtle berries, with the perspective of producing a functional ingredient, dietary supplement or pharmaceutical preparation. The antioxidant activity was preliminarily evaluated through in vitro assays, further confirmed through ex vivo analysis on murine fibroblasts, and the profile of phenol compounds was characterized.
\end{abstract}

Results: Myrtle berries homogenate, containing yeast extract (0.4\%, wt/vol), was fermented with Lactobacillus plantarum C2, previously selected from plant matrix. Chemically acidified homogenate, without bacterial inoculum and incubated under the same conditions, was used as the control. Compared to the control, fermented myrtle homogenate exhibited a marked antioxidant activity in vitro. The radical scavenging activity towards DPPH increased by $30 \%$, and the inhibition of linoleic acid peroxidation was twice. The increased antioxidant activity was confirmed using Balb 3 T3 mouse fibroblasts, after inducing oxidative stress, and determining cell viability and radical scavenging activity through MTT and DCFH-DA assays, respectively. The lactic acid fermentation allowed increased concentrations of total phenols, flavonoids and anthocyanins, which were 5-10 times higher than those found for the non-fermented and chemically acidified control. As shown by HPLC analysis, the main increases were found for gallic and ellagic acids, and flavonols (myricetin and quercetin). The release of these antioxidant compounds would be strictly related to the esterase activities of $L$. plantarum.

Conclusions: The lactic acid fermentation of myrtle berries is a suitable tool for novel applications as functional food dietary supplements or pharmaceutical preparations.

Keywords: Myrtle, Fermentation, Lactic acid bacteria, Antioxidant activity

\section{Background}

Myrtle (Myrtus communis L.) is a medicinal and aromatic plant belonging to Myrtaceae family, which is largely diffused in the Mediterranean areas and mainly cultivated in Tunisia and Italy [1]. Nowadays, leaves and berries are largely used as spice, in food processing [2] and cosmetic industry [3]. In Italy, especially in Sardinia, berries and leaves are used for the manufacture of two celebrated liquors, named Mirto rosso and Mirto bianco [1]. In traditional medicine, myrtle is frequently consumed

\footnotetext{
*Correspondence: carlogiuseppe.rizzello@uniba.it

'Dipartimento di Scienze del Suolo, della Pianta e degli Alimenti, University of Bari, Via G. Amendola 165/a Bari 70126, Italy

Full list of author information is available at the end of the article
}

as infusion and decoction [4]. The infusion of leaves is considered stimulant, antiseptic, astringent and hypoglycemic. It is also used to treate eczema, psoriasis, asthma, gastrointestinal disorders, urinary infections and diarrhea [5]. The leaf decoction is still used for vaginal washing, enemas and against respiratory diseases [6]. The decoction from fruits is used as antidiarrheal, antihemorrhoidal agents, and to treat mouth and eyes diseases [5]. Traditionally, flowers are used for the treatment of varicose veins [4].

Despite the well-established use of myrtle in traditional medicine and the increasing scientific interest, there is a lack of summarized data on the functional compounds 
coming from the different preparations, therapeutical applications, and the possible risks regarding the use [7].

The different parts of the Myrtus communis plant were chemically characterized, and several bioactive compounds were found at various levels. Leaf and flowers are rich in essential oils, tannins, phenolic acids and flavonoids $[8,9]$. Fruits are rich of volatile compounds, tannins, sugars, anthocyanins, fatty acids and organic acids such as citric and malic acids [2]. Several studies have focused the antioxidant, antimicrobial and anticancer features of various myrtle extracts $[1,10]$, with emphasis on essential oils and organic solvent extracts. Recently, the phytochemical composition and biological activities of a myrtle infusion [1], the most common preparation for using berries and leaves, were also investigated. A potential dietary source for health-protective compounds was claimed [1].

Based on the above literature, two main priorities would emerge. First, the myrtle potential antioxidant activity should be better defined and, possibly, enhanced. Second, standardized and novel formulations for traditional or innovative commercial applications should be exploited [11].

Lactic acid bacteria and, more in general, the lactic acid fermentation is considered as one of the most suitable tool to exploit the biogenic/functional potential of plant matrices and to enrich them with bioactive compounds [12]. Indeed, the fermentation by selected lactic acid bacteria was largely used to enhance the antimicrobial, antioxidant and immune-modulatory features of several cereal, pseudo-cereal and leguminous flours as well as of medicinal plants like Echinacea spp. [11].

To the best of our knowledge, no studies have already considered the use of the lactic acid fermentation to enhance the functional features of $M$. communis. This study aimed at using a selected lactic acid bacterium for increasing the antioxidant features of myrtle berries, with the perspective of producing a functional ingredient, dietary supplement or pharmaceutical preparation. The antioxidant activity was preliminarily evaluated through in vitro assays, further confirmed through ex vivo analysis on murine fibroblasts, and the profile of phenol compounds was characterized.

\section{Results}

\section{Myrtle fermentation}

The homogenate of myrtle berries with distilled water (pH $5.08 \pm 0.21$ ) allowed a very poor growth of L. plantarum $\mathrm{C} 2$ (initial cell density $5 \times 10^{7} \mathrm{cfu} / \mathrm{ml}$ ) at $30^{\circ} \mathrm{C}$. The addition of glucose (1\%) did not lead to significant $(P<0.05)$ variation of both the values of $\mathrm{pH}$ and cell density after 24 or $48 \mathrm{~h}$ of incubation. Contrarily, when yeast extract $(0.4 \%, \mathrm{wt} / \mathrm{vol})$ was added to homogenate, the cell density of the starter increased by ca. 2 logarithmic cycles after $24 \mathrm{~h}$, remaining stable up to $48 \mathrm{~h}$ of incubation. The value of $\mathrm{pH}$ decreased to $4.56 \pm 0.32$ and $3.40 \pm 0.28$, respectively after 24 and $48 \mathrm{~h}$ of fermentation. Enterobacteria were not detectable by plate count in $1 \mathrm{ml}$ of homogenate. All further experiments referred to myrtle homogenate, which was supplemented with yeast extract and fermented for $48 \mathrm{~h}$ (optimal culture conditions).

Under the above optimal conditions, the kinetic of acidification was characterized by values of $A(\Delta \mathrm{pH})$, latency phase duration ( $\lambda$, expressed in hours), and $\mathrm{V}_{\max }$ $(\Delta \mathrm{pH} / \mathrm{h})$ of $0.58 \pm 0.02,0.92 \pm 0.3$, and $0.09 \pm 0.02$, respectively. The parameters for the kinetic of growth were: A, $2.21 \pm 0.05 \log \mathrm{cfu} / \mathrm{g} ; \lambda, 0.72 \pm 0.03 \mathrm{~h}$; and $\mu_{\max }$, $0.32 \pm 0.04(\Delta \log \mathrm{cfu} / \mathrm{g} / \mathrm{h})$.

\section{In vitro antioxidant activity}

A myrtle homogenate fermented for $48 \mathrm{~h}$ at $30^{\circ} \mathrm{C}$ with $\mathrm{L}$. plantarum C2 (Mf) and a myrtle homogenate noninoculated and chemically acidified, incubated under the same conditions (Mct), were assayed for the antioxidant activity in vitro by three different methods.

First, the antioxidant activity was assayed as radical scavenging activity on stable 2,2-diphenyl-1-picrylhydrazyl (DPPH) radical. The analysis was carried out using methanol extracts (ME). During radical scavenging assay, the colored stable DPPH radical is reduced to nonradical DPPH-H, when in the presence of an antioxidant or a hydrogen donor. DPPH radical, without antioxidants, was stable over the time. Under the assay conditions, the $100 \%$ of activity corresponded to the complete scavenging of DPPH radical (50 $\mu \mathrm{M}$ final concentration) after $10 \mathrm{~min}$ of incubation with the antioxidant compounds. According to previous studies [11,13], the color intensity of $\mathrm{DPPH}^{*}$ showed a logarithmic decline when it was in the presence of butylated hydroxytoluene (BHT). The activity of Mct was significantly $(P<0.05)$ lower than that of BHT, which was used as the positive control, and had a radical scavenging activity towards the stable radical DPPH of $76 \pm 1 \%$ (Table 1). Fermentation significantly $(P<0.05)$ increased the radical scavenging activity, it was ca. $5 \%$ higher than BHT.

The quantification of the inhibition of linoleic acid peroxidation was also used to measure the antioxidant activity. Lipid peroxidation is thought to proceed via radical mediated abstraction of hydrogen atoms from methylene carbons in polyunsaturated fatty acids [14]. The antioxidant activity of the ME from Mct did not significantly $(P>0.05)$ differed from that of the BHT that was used as the positive control $(55 \pm 2 \%)$. When Mf was used, the inhibition of the linoleic acid peroxidation significantly $(P<0.05)$ increased (Table 1$)$.

The total antioxidant capacity of Mct and Mf was then determined based on the scavenging activity towards radical cation 2,2'-azino-di-[3-ethylbenzthiazoline sulphonate] 
Table 1 In vitro antioxidant activity

\begin{tabular}{llll}
\hline & $\begin{array}{l}\text { DPPH radical scavenging } \\
\text { activity (\%) }\end{array}$ & $\begin{array}{l}\text { Lipid peroxidation } \\
\text { inhibitory activity (\%)* }\end{array}$ & $\begin{array}{l}\text { Radical cation ABTS }{ }^{+} \text {scavenging } \\
\text { activity (mM Trolox equiv.) }\end{array}$ \\
\hline BHT & $76 \pm 1^{\mathrm{b}}$ & $55 \pm 2^{\mathrm{b}}$ & nd \\
Mct & $60 \pm 2^{\mathrm{c}}$ & $52 \pm 3^{\mathrm{b}}$ & $26.6 \pm 0.1^{\mathrm{b}}$ \\
Mf & $81 \pm 3^{\mathrm{a}}$ & $84 \pm 3^{\mathrm{a}}$ & $56.6 \pm 0.2^{\mathrm{a}}$ \\
\hline
\end{tabular}

Radical scavenging activity towards $\mathrm{DPPH}^{*}$, linoleic acid peroxidation inhibitory activity, and radical cation $\mathrm{ABTS}^{+}$scavenging activity of the myrtle homogenate fermented for $48 \mathrm{~h}$ at $30^{\circ} \mathrm{C}$ with Lactobacillus plantarum C2 (Mf). The chemically acidified myrtle homogenate, without bacterial inoculum, and incubated for $48 \mathrm{~h}$ at $30^{\circ} \mathrm{C}$ (Mct), was the control. Butylatedhydroxytoluene (BHT) was used as antioxidant reference.

Data are the mean of three independent analyses.

Nd: not determined.

* determined on methanol extracts (ME).

${ }^{\mathrm{a}-\mathrm{C} V a l u e s}$ with different superscript letters, in the same column, differ significantly $(P<0.05)$.

(ABTS) [15]. ABTS assay is based on the formation of the ferryl myoglobin radical from metmyoglobin and hydrogen peroxide, which causes the oxidation of ABTS to $\mathrm{ABTS}^{\cdot+}$, the chromogen radical cation. In the presence of an antioxidant agent such as Trolox (water-soluble vitamin $\mathrm{E}$ analog), the chromogenic reaction is suppressed. The ABTS scavenging activity of the Mf was twice with respect to that found for Mct (Table 1).

\section{Cytotoxicity}

Aiming at determining the cytotoxicity of myrtle extracts, the cell viability of the mouse fibroblasts Balb3T3 was assayed after the exposure to freeze-dried Mct and Mf. The concentrations ranged from 0.1 to $100 \mathrm{mg} / \mathrm{ml}$. The fibroblast viability was determined through the MTT (3(4,5-dimethyl-2-yl)-2,5-diphenyltetrazolium bromide) assay (Figure 1). Compared to the control (untreated cells in basal medium), the treatment with Mct for $24 \mathrm{~h}$ at concentrations higher than $50 \mathrm{mg} / \mathrm{ml}$ induced a significant $(P<0.05)$ cytotoxicity on fibroblasts. Cytotoxicity corresponded to the effect causing a decrease of the cell viability below $70 \%$. At concentrations higher than $10 \mathrm{mg} / \mathrm{ml}$, the cytotoxicity was manifested when the treatment was extended to $72 \mathrm{~h}$. Nevertheless, a treatment lasting $48 \mathrm{~h}$ with Mct at concentrations lower than $10 \mathrm{mg} / \mathrm{ml}$ induced a significant $(P<0.05)$ proliferation of the cell cultures. When Mf was used (Figure 1), no cytotoxic effect was found at concentrations lower than $50 \mathrm{mg} / \mathrm{ml}$, independently from the time of incubation. Cell proliferation was found when fibroblasts were treated for $48 \mathrm{~h}$ with $\mathrm{Mf}$ at concentrations lower than $10 \mathrm{mg} / \mathrm{ml}$.

\section{Protective effect towards oxidative-induced stress in Balb3T3 cells}

To further investigate the capacity of myrtle extracts to act as radical scavenger, Balb $3 \mathrm{~T} 3$ cells were grown in the presence of freeze-dried Mct and Mf. Afterwards, cells were treated with hydrogen peroxide. Concentrations higher than $10 \mathrm{mg} / \mathrm{ml}$ were not assayed to avoid cytotoxic effects. Cell viability was assayed through the

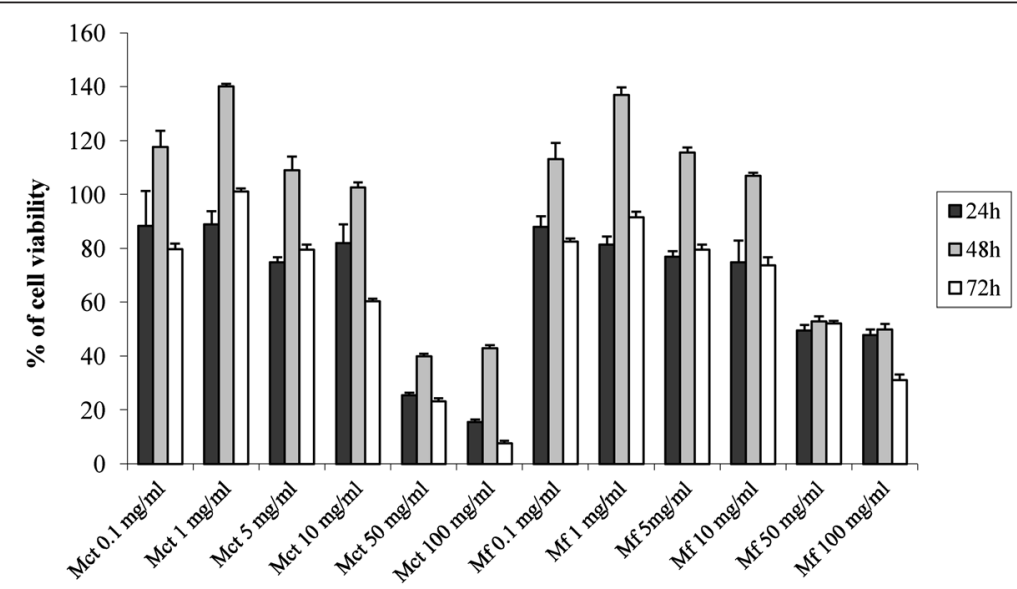

Figure 1 Cell viability of mouse fibroblasts. Effect of different concentrations $(0.1-100 \mathrm{mg} / \mathrm{ml})$ of freeze-dried myrtle berry homogenates on the cell viability of mouse fibroblasts. Mouse fibroblasts were cultured in Dulbecco's Modified Eagle Medium (DMEM), and incubated with re-suspended freeze-dried homogenates for 24,48 , and $72 \mathrm{~h}$. The percentage of viable cells was measured through the 3-(4,5-dimethylthiazol-2-yl)-2,5diphenyltetrazolium bromide (MTT) assay. A myrtle homogenate fermented for $48 \mathrm{~h}$ at $30^{\circ} \mathrm{C}$ with Lactobacillus plantarum C2 (Mf) and a myrtle homogenate non-inoculated and chemically acidified, incubated under the same conditions (Mct), were assayed. $a$-Tocopherol (a-tp, 250,500 , and $100 \mu \mathrm{M}$ ) was used as the positive control. Data are the means of three independent experiments twice analysed. 
capacity of functional mitochondria to catalyze the reduction of MTT to formazan salt via mitochondrial dehydrogenases. Compared to the negative control $(68.8 \pm 2.1 \%$ of cell viability after oxidative stress), $\alpha$-tocopherol and both the myrtle extracts significantly $(P<0.05)$ increased cell survival (Figure 2). Overall, the protective effect of Mct was significantly $(P<0.05)$ lower than that of $\mathrm{Mf}$ for all the concentrations assayed. In particular, Mf at concentrations of 5 and $10 \mathrm{mg} / \mathrm{ml}$ induced the highest cell viability $(87.7 \pm 1.2$ and $103.2 \pm 1.3 \%$, respectively). The activity of Mf was also significantly $(P<0.05)$ higher than that found with $\alpha$-tocopherol, which was assayed at concentrations ranging from 250 to $1000 \mu \mathrm{g} / \mathrm{ml}$.

\section{Intracellular reactive oxygen species (ROS) generation}

To determine the potential of myrtle extract against oxidative stress-mediated injuries, Balb3T3 cells were pretreated with Mct, Mf or $\alpha$-tocopherol, further incubated with 2,7'-dichlorofluorescein diacetate (DCFH-DA), and stressed with $\mathrm{H}_{2} \mathrm{O}_{2}$. DCFH-DA was used as a probe to assess the formation of intracellular hydrogen peroxide by flow cytometry. The assay correlates to the emitted fluorescence with the ROS intracellular production and, consequently, to the antioxidant activity of the samples [16]. Data are reported as percentage of radical scavenging activity (RSA) with respect to the control $\left(\mathrm{H}_{2} \mathrm{O}_{2}\right.$ stressed cells). As expected, cells pre-treated with $\alpha$ tocopherol showed RSA higher than 80\% (Figure 3). Similar values were found when Mct was used at concentrations ranging from 5 to $10 \mathrm{mg} / \mathrm{ml}$. The highest activity was found for Mf. When the pre-treatment was carried out with 5 or $10 \mathrm{mg} / \mathrm{ml}$ of Mf, RSA higher than $92 \%$ and significantly $(P<0.05)$ higher than those found for Mct and 0.5-1 $\mathrm{mM} \alpha$-tocopherol were observed.

\section{Phenolic compounds composition}

Myrtle extracts were analyzed for the concentration of total phenols. A markedly significant $(P<0.05)$ increase was found when $L$. plantarum $\mathrm{C} 2$ was used as starter for fermentation. Indeed, Mf contained an amount of total phenols ca. 5-times higher than that of Mct (Table 2).

Lactic acid fermentation also positively affected the concentration of total flavonoids and total anthocyanins. These compounds were, respectively, found at levels ca. 5- and 10-times higher than those of $\mathrm{Mf}$ (Table 2).

Free phenolic acids and flavonols of Mf were determined by HPLC and their concentrations were compared to those that were present in Mct. The highest concentrations were found for ellagic and gallic acids, which were ca. 2- and 3-times higher than those of Mct (Table 2). Also the concentrations of vanillic, and syringic acids were the highest in Mf. Flavonols (myricetin and quercetin) increased by ca. 2- and 4times in Mf, reaching levels of $2.56 \pm 0.03$ and $0.79 \pm$ $0.02 \mathrm{mg} / \mathrm{g}$ of $\mathrm{dm}$, respectively (Table 2 ). The flavanol catechin did not significantly $(P>0.05)$ increase during fermentation.

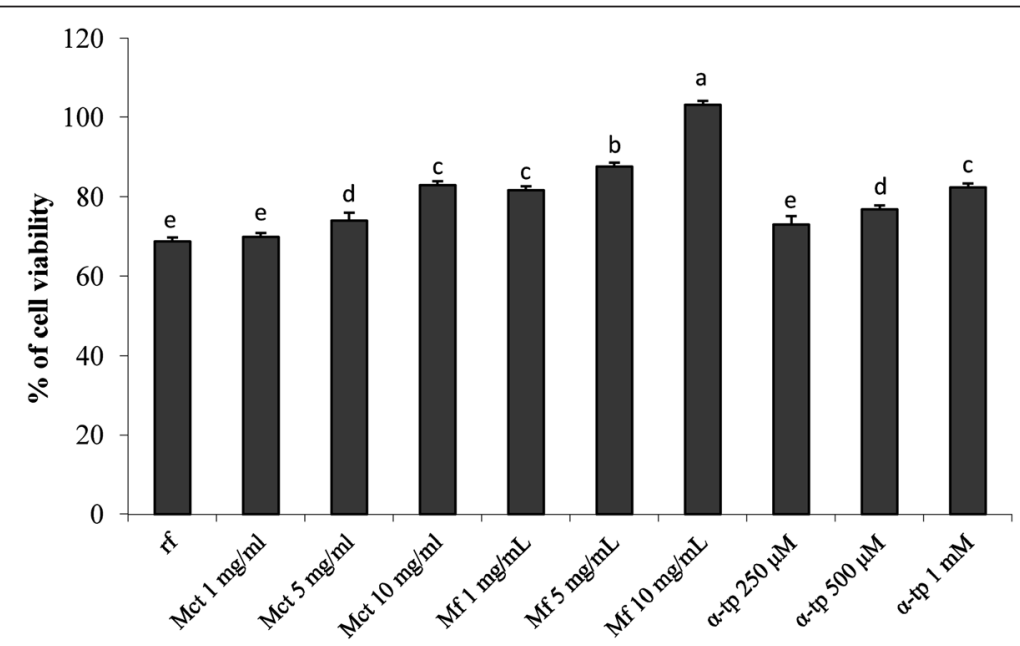

Figure 2 Effect on mouse fibroblasts after induced oxidative stress. Effect of different concentrations (1-10 mg/ml) of freeze-dried myrtle berry homogenates on the cell viability of mouse fibroblasts after oxidative stress. Mouse fibroblasts were cultured in Dulbecco's Modified Eagle Medium (DMEM), and incubated with re-suspended freeze-dried homogenates for $16 \mathrm{~h}$. Oxidative stress was artificially induced by incubating cultured cells with $400 \mu \mathrm{M}$ hydroxide peroxide for $2 \mathrm{~h}$. The percentage of viable cells was measured through the 3-(4,5-dimethylthiazol-2-yl)-2,5-diphenyltetrazolium bromide (MTT) assay. The viability of $\mathrm{H}_{2} \mathrm{O}_{2}$-stressed cells incubated without antioxidant compounds (reference, rf) was also included. A myrtle homogenate fermented for $48 \mathrm{~h}$ at $30^{\circ} \mathrm{C}$ with Lactobacillus plantarum C2 (Mf) and a myrtle homogenate non-inoculated and chemically acidified, incubated under the same conditions (Mct), were assayed at concentration ranging from 1 to $10 \mathrm{mg} / \mathrm{ml}$. a-Tocopherol (a-tp; 250,500, and 1000 $\mu \mathrm{M}$ ) was used as the positive control. rf: $\mathrm{H}_{2} \mathrm{O}_{2}$-stressed cells. Data are the means of three independent experiments twice analysed. ${ }^{\text {a-e }} \mathrm{Columns}$ with different superscript letters differ significantly $(P<0.05)$. 


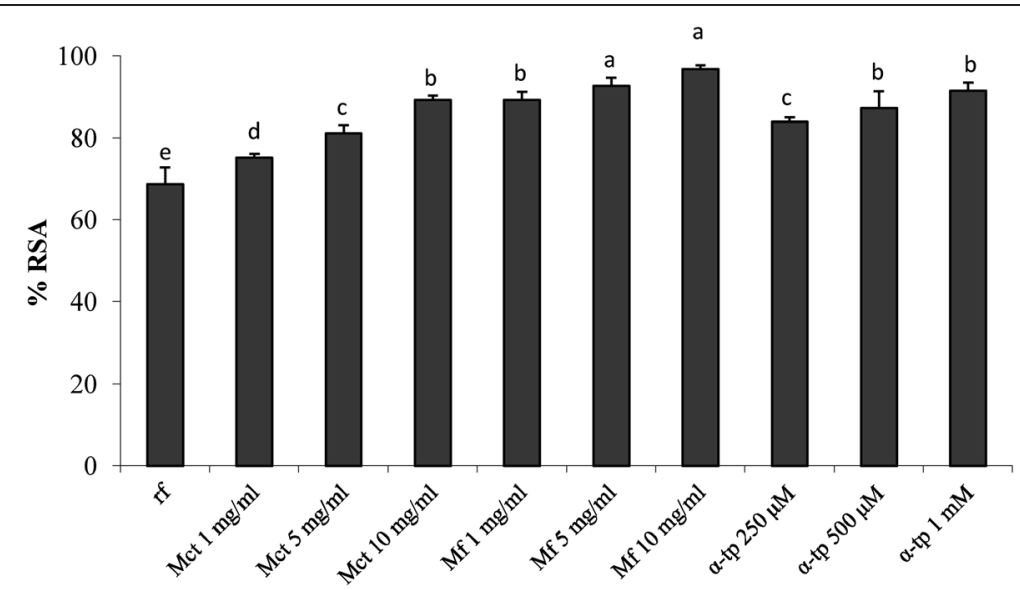

Figure 3 Radical scavenging activity on mouse fibroblasts. Effect of different concentrations (1-10 mg/ml) of freeze-dried myrtle berry homogenates on the radical scavenging activity (RSA) of mouse fibroblasts after oxidative stress, as estimated by $2^{\prime}, 7^{\prime}$-dichlorofluorescein diacetate (DCFH-DA) assay. Mouse fibroblasts were cultured in Dulbecco's Modified Eagle Medium (DMEM), and incubated with re-suspended freeze-dried homogenates for $16 \mathrm{~h}$. Oxidative stress was artificially induced by incubating cultured cells with $400 \mu \mathrm{M}$ hydroxide peroxide for $2 \mathrm{~h}$. The percentage of viable cells was measured through the 3-(4,5-dimethylthiazol-2-yl)-2,5-diphenyltetrazolium bromide (MTT) assay. The RSA of the $\mathrm{H}_{2} \mathrm{O}_{2}$-stressed cells incubated without antioxidant compounds (reference, if) was also included. A myrtle homogenate fermented for $48 \mathrm{~h}$ at $30^{\circ} \mathrm{C}$ with Lactobacillus plantarum C2 (Mf) and a myrtle homogenate non-inoculated and chemically acidified, incubated under the same conditions (Mct), were assayed at concentration ranging from 1 to $10 \mathrm{mg} / \mathrm{ml}$. a-Tocopherol (a-tp; 250, 500, and $1000 \mu \mathrm{M}$ ) was used as the positive control. If: $\mathrm{H}_{2} \mathrm{O}_{2}$-stressed cells. Data are the means of three independent experiments twice analysed. ${ }^{\text {a-e }}$ Columns with different superscript letters differ significantly $(P<0.05)$.

\section{Discussion}

Health benefits from fermentation, also in the case of plant materials, are usually direct, through interaction of ingested live microorganisms with the host (probiotic effect), or indirect as the result of the ingestion of

Table 2 Phenolic compouds profile

\begin{tabular}{lcc}
\hline Phenolic compounds & Mct & Mf \\
\hline Total phenols (GAE/g dm*) & $135.49 \pm 2.35^{\mathrm{b}}$ & $669.38 \pm 4.19^{\mathrm{a}}$ \\
Total flavonoids (RE/g dm) & $20.39 \pm 3.40^{\mathrm{b}}$ & $113.30 \pm 2.6^{\mathrm{a}}$ \\
Total anthocyanins (TAC/g dm) & $4.98 \pm 0.63^{\mathrm{b}}$ & $52.75 \pm 1.33^{\mathrm{a}}$ \\
Phenolic acids & & \\
Gallic acid (mg/g dm) & $0.17 \pm 0.03^{\mathrm{b}}$ & $0.55 \pm 0.02^{\mathrm{a}}$ \\
Vanillic acid (mg/g dm) & $0.10 \pm 0.02^{\mathrm{b}}$ & $0.28 \pm 0.02^{\mathrm{a}}$ \\
Syringic acid (mg/g dm) & $0.14 \pm 0.04^{\mathrm{b}}$ & $0.28 \pm 0.02^{\mathrm{a}}$ \\
Ellagic acid (mg/g dm) & $1.44 \pm 0.03^{\mathrm{b}}$ & $2.78 \pm 0.04^{\mathrm{a}}$ \\
Flavonols/Flavano/s & & \\
Myricetin (mg/g dm) & $1.11 \pm 0.02^{\mathrm{b}}$ & $2.56 \pm 0.03^{\mathrm{a}}$ \\
Quercetin (mg/g dm) & $0.20 \pm 0.01^{\mathrm{b}}$ & $0.79 \pm 0.02^{\mathrm{a}}$ \\
Catechin (mg/g dm) & $1.12 \pm 0.02$ & $1.26 \pm 0.03$ \\
\hline
\end{tabular}

Phenolic compounds of the myrtle homogenate fermented for $48 \mathrm{~h}$ at $30^{\circ} \mathrm{C}$ with Lactobacillus plantarum $\mathrm{C} 2$ (Mf). The chemically acidified myrtle homogenate, without bacterial inoculum, and incubated for $48 \mathrm{~h}$ at $30^{\circ} \mathrm{C}$ (Mct), was the control.

*dm: dry matter;

GAE: gallic acid equivalents.

RE: rutin equivalents.

TAC: total anthocyanins content.

${ }^{a-b}$ Values with different superscript letters, in the same row, differ significantly $(P<0.05)$. microbial metabolites, which are synthesized during fermentation (biogenic effect) [17]. Under optimal processing conditions, microbes may contribute to plant functionality through their enzyme portfolio, which promotes the synthesis of various metabolites and/or the release of functional compounds that are cryptic in the raw matrix [17]. Recently, lactic acid bacteria were used to synthesize $\gamma$-amino butyric acid (GABA) from grape must [18], isoflavone, aglycones and equol from soy milk, antioxidant and anti-hypertensive peptides, and lunasin from various cereal and pseudo-cereal flours $[19,20,21]$.

A large number of plants were screened to be sources of novel phenolic compounds for alimentary, cosmetic and pharmaceutical uses [22]. First, this study reported the capacity of a lactic acid bacterium to enhance the antioxidant properties and the phenol profile of myrtle berries. A selected strain of Lactobacillus plantarum, which was demonstrated to well adapt to plant matrices rich of polyphenols $[13,19,23,24]$, was used. The concentration of fermentable carbohydrates of myrtle berries was enough to allow bacterial growth, but the addition of yeast extract to the homogenate was needed to get the optimal growth of L. plantarum C2.

Oxidative stress and lipid peroxidation are believed to play a significant role in the development of tissue damage and in several pathologies of the human body [22]. Antioxidant activities of fermented myrtle berries were investigated, and compared to a non-inoculated and chemically acidified control. Chemical acidification was 
carried out to exclude the effect of the $\mathrm{pH}$ on the antioxidant activity and phenol extractability from myrtle homogenate. The concentration of phenols largely varies among the different parts of the same plant (leaf, roots, berries), and is affected by genetic, environmental (e.g., light, temperature, agronomic practices), and processing factors (drying temperature, extraction methods, formulation and storage conditions) [25,26]. Myrtle is a rich source of phenols, and hydrolysable tannins and flavonoids are present in seed and pericarp, respectively [27]. The antioxidant activity of a plant extract is not usually related to a single phenolic compound [22]. Several in vitro studies indicated that flavonoids, coumarines, phenolic acid, lignans, hydroxycinnamates and stilbenes have altogether antioxidant activity [22]. The antioxidant capacity of phenols is mainly due to their redox properties, which allow them to act as reducing agents, hydrogen donors, and singlet oxygen quenchers [22].

The antioxidant activity of myrtle homogenate was first estimated in vitro. The radical scavenging activity of the extract fermented with L. plantarum $\mathrm{C} 2$ was markedly higher than that of the non-fermented homogenate, and it reached almost the same value of the synthetic antioxidant. A marked inhibition of the linoleic acid peroxidation as well as a relevant total antioxidant capacity (estimated towards ABTS radical) were also found, confirming the positive effect of the lactic fermentation.

The effect of phenols on cell proliferation and cytotoxicity is largely investigated and debated, aiming at explaining the potential protective role towards oxidative stresses and tumor development [28]. The MTT assay on mouse fibroblasts Balb3T3 was used to determine the cytotoxicity of the myrtle extracts. As expected, a cytotoxic effect was found for high concentrations $(>50 \mathrm{mg} / \mathrm{ml}$ ) of fermented and freeze-dried myrtle extract. A proliferative effect occurred at lower concentrations, with treatment lasting $48 \mathrm{~h}$. The MTT assay on mouse fibroblasts was also used to show the protective effect of the fermented myrtle extract towards induced oxidative stress. The antioxidant effect on cultured cells was higher than that of the non-fermented homogenate and also higher than that of $\alpha$-tocopherol, which was used at concentrations up to $1 \mathrm{mg} / \mathrm{ml}$. The protective effect was investigated through the determination of the intracellular ROS production and detoxification by DCFH-DA assay. Also in this case, it was confirmed the markedly higher antioxidant activity on mouse fibroblasts compared to the non-fermented myrtle extract. Clearly, the antioxidant potential of myrtle berries has also to be partially attributed to the inherent phenols contained in the raw matrix [1]. Nevertheless, all the above results showed that fermentation by L. plantarum C2 caused a modification of the phenol profile of marked significance.
Aiming at explaining the increase of the antioxidant activity due to lactic acid fermentation, the phenolic fraction of myrtle extracts was characterized. The fermentation caused an increase of the concentration of total phenols, which was ca. 5-times higher than that found in the non-fermented homogenate. As expected, the same trend was found for flavonoids and anthocianins. These latter compounds, which are responsible for the dark blue color of myrtle berries and extracts [27] increased by ca. 10 times. The lactic acidification cannot be considered as the main cause for the above increase, since also the non-fermented homogenate was chemically acidified. The increase of the solubility of phenols due to biological acidification was already reported for many plant matrices $[25,26]$. The capacity of L. plantarum to degrade polyphenolic compounds was already documented and considered as a metabolic strategy for adapting to environmental hostile niches [29,30]. All phenolic acids increased, but mainly gallic and ellagic acids. Both these compounds may be released via tannase activity. Tannase or tannin acyl hydrolase (EC 3.1.1.20) catalyzes the hydrolysis of ester bonds that are present in hydrolysable tannins and gallic acid esters. First, Osawa et al. [31] showed the presence of tannase activity in L. plantarum isolates. Later, this capacity was confirmed in other strains, which were isolated from various food matrices $[32,33,34]$. The route to degrade tannins by $L$. plantarum implies that tannic acid is hydrolyzed to gallic acid and glucose, and the gallic acid formed is further decarboxylated to pyrogallol [35]. This pathway implies the presence of tannase and gallate decarboxylases, whose presence was previously documented in L. plantarum [31]. Although the metabolism of L. plantarum towards phenolic compounds is not completely elucidated [36], it may be hypothesized that the increase of the other phenolic acids (vanillic and syringic acids) and flavonols (myricetin and quercetin) depends on feruloyl esterases that are active on complex phenolic molecules or glycosylated forms. These latter are very abundant in myrtle fruits [1,37]. It was observed that flavol aglycones (e.g., myricetin and quercetin) contain multiple $\mathrm{OH}$ groups and show higher antioxidant activity than their glycosides (e.g., rutin and myricitrin) [2]. Feruloyl esterases are widespread in L. plantarum strains, and allow to metabolize compounds that are abundant in fermented plant matrices (e.g., hydroxycinnamoyl esters) [36]. Similar effects by lactic acid bacteria on plant phenols were documented for cowpeas [38], onions [39], pomegranate [40], and wheat flour [26]. Catechin, a flavanol largely present in many fruits [41], was not affected by lactic acid fermentation. Contrarily to other classes of flavonoids, flavanols are not glycosylated in plant matrices [42], thus excluding a role of the esterase activity. 


\section{Conclusions}

Nutraceutical industry and preventive medicine are currently showing a marked interest for natural antioxidant compounds because of their potential application in food, cosmetic and pharmaceutical products to replace synthetic carcinogenous antioxidants [7]. The demand for dietary phytonutrients encourages the exploitation of plant potential through lactic acid fermentation [12]. In agreement with this perspective, this study demonstrates how the antioxidant properties of myrtle berries could be enhanced through lactic acid fermentation. Depending on the application, the fermented myrtle berry homogenate may be used as such or, separated from the solid phase, as supernatant (in aqueous or freeze-dried forms). Although in vivo assay should be further carried out, novel applications as functional food dietary supplements or pharmaceutical preparations of the fermented myrtle berries should be warranted.

\section{Methods}

Microorganisms and culture conditions

Lactobacillus plantarum $\mathrm{C} 2$, which was previously isolated from carrots, identified by partial sequencing of $16 \mathrm{~S}$ rRNA, and selected for vegetable fermentations $[11,23,24,42,43]$, was used in this study. The strain belongs to the Culture Collection of the Department of Soil, Plant, and Food Sciences (Bari, Italy). L. plantarum $\mathrm{C} 2$ was cultivated at $30^{\circ} \mathrm{C}$ onto MRS broth (Oxoid, Basingstoke, Hampshire, United Kingdom). When used for fermentation, lactic acid bacteria cells were cultivated until the late exponential phase of growth was reached (ca. $10 \mathrm{~h}$ ), washed twice in $50 \mathrm{mM}$ phosphate buffer, $\mathrm{pH}$ 7.0, and re-suspended in the liquid substrate. Enumeration of lactic acid bacteria was carried out by plating onto MRS agar at $30^{\circ} \mathrm{C}$ for $48 \mathrm{~h}$. Total enterobacteria were determined on Violet Red Bile Glucose Agar (VRBGA, Oxoid) at $37^{\circ} \mathrm{C}$ for $24 \mathrm{~h}$.

\section{Fermentation}

Ripe berries were collected manually (autumn 2013) from spontaneous Myrtus communis plants harvested in Sardinia, Italy, and stored at $-20^{\circ} \mathrm{C}$ until they were used as substrate for fermentation. The substrate was obtained as reported by Liu et al. [44], with some modifications. In details, myrtle berries were added to distilled water $(1: 1, \mathrm{wt} / \mathrm{wt})$ and homogenized using a Stomacher 400 lab blender (Seward Medical, London) for $10 \mathrm{~min}$. The homogenate was kept at $4^{\circ} \mathrm{C}$ for $2 \mathrm{~h}$. Then, the homogenate was inoculated with the starter, without any supplementation (i), or with the addition of $0.4 \%$ (wt $/ \mathrm{vol}$ ) yeast extract (Oxoid) (ii), or $1 \%$ glucose (wt/vol) (iii). The initial cell density of the lactic acid bacterium was of ca. $5 \times 10^{7} \mathrm{cfu} / \mathrm{ml}$. Fermentation (Mf) was allowed at $30^{\circ} \mathrm{C}$ for $48 \mathrm{~h}$, under stirring conditions (120 rpm). An homogenate without bacterial inoculum, and chemically acidified with lactic acid (final pH 4.0), was incubated under the same conditions and used as the control (Mct). Mct and Mf were centrifuged $(10,000 \times g$ for $20 \mathrm{~min})$ at $4^{\circ} \mathrm{C}$, and the supernatants were used for analyses.

\section{Kinetics of growth and acidification}

Kinetics of growth and acidification were determined and modelled in agreement with the Gompertz equation, as modified by Zwietering et al. [45]: $y=\mathrm{k}+\mathrm{A}$ $\exp \{-\exp [(\mu \max$ or $V \max \mathrm{e} / \mathrm{A})(\lambda-\mathrm{t})+1]\}$; where $y$ is the growth expressed as $\log \mathrm{cfu} / \mathrm{g}$ or the acidification rate expressed as $\mathrm{dpH} / \mathrm{dt}$ (units of $\mathrm{pH}$ ) at the time $\mathrm{t}$; $\mathrm{k}$ is the initial level of the dependent variable to be modelled (log $\mathrm{cfu} / \mathrm{g}$ or $\mathrm{pH}$ units); $\mathrm{A}$ is the cell density or $\mathrm{pH}$ (units) variation (between inoculation and the stationary phase); $\mu_{\max }$ or $V_{\max }$ is the maximum growth rate expressed as $\Delta \log$ $\mathrm{cfu} / \mathrm{g} / \mathrm{h}$ or the maximum acidification rate expressed as $\mathrm{dpH} / \mathrm{h}$, respectively; $\lambda$ is the length of the lag phase measured in hours. The experimental data were modelled by the non-linear regression procedure of the Statistica 8.0 software (Statsoft, Tulsa, USA).

\section{Antioxidant activity in vitro}

First, the antioxidant activity of myrtle homogenates was evaluated in vitro using different methods.

The free radical scavenging capacity was determined on methanol extract (ME) using the stable 2,2-diphenyl1-picrylhydrazyl radical $\left(\mathrm{DPPH}^{\circ}\right)$. ME were prepared resuspending $1 \mathrm{mg}$ of freeze-dried Mct or Mf in $1 \mathrm{ml}$ of $80 \%$ methanol. The protocol previously reported by $\mathrm{Yu}$ et al. [46] was used [11]. The reaction was monitored by reading the absorbance at $517 \mathrm{~nm}$ every $2 \mathrm{~min}$ for $30 \mathrm{~min}$. A blank reagent was used to verify the stability of $\mathrm{DPPH}^{\cdot}$ over the test time. The absorbance value measured after $10 \mathrm{~min}$ was used for the calculation of the $\mu$ moles $\mathrm{DPPH}^{\circ}$ scavenged by extracts. Butylated hydroxytoluene (BHT, $75 \mathrm{ppm}$ ) was used as the antioxidant reference $[11,13,25]$.

The antioxidant activity of ME was also measured according to the method of Osawa and Namiki [47], with some modification [11]. One $\mathrm{ml}$ of $\mathrm{ME}$ was added to $1 \mathrm{ml}$ of linoleic acid $(50 \mathrm{mM})$, previously dissolved in ethanol (99.5\%). Incubation in glass test tube, tightly sealed with silicone rubber cap, was allowed at $60^{\circ} \mathrm{C}$ in the dark for 8 days. The degree of oxidation was determined by measuring the value of ferric thiocyanate, according to Mitsuta et al. [48]. One hundred microliters of the above sample were mixed with $4.7 \mathrm{ml}$ of $75 \%(\mathrm{v} / \mathrm{v})$ ethanol, $0.1 \mathrm{ml}$ of $30 \%(\mathrm{w} / \mathrm{v})$ ammonium thiocyanate and $0.1 \mathrm{ml}$ of $0.02 \mathrm{M}$ ferrous chloride, dissolved in $1 \mathrm{M} \mathrm{HCl}$. After $3 \mathrm{~min}$, the color development (degree of linoleic acid oxidation) was measured spectrophotometrically at $500 \mathrm{~nm}$. BHT $(1 \mathrm{mg} / \mathrm{ml})$ was used as the antioxidant 
references. A negative control (without antioxidant) was also considered. The inhibition effect was expressed as follows: inhibition of linoleic acid autoxidation (\%) $=[$ (negative control absorbance - sample absorbance)/negative control absorbance] $\times 100$.

Finally, the radical cation (2,2'-azino-di-[3-ethylbenzthiazoline sulphonate]) $\left(\mathrm{ABTS}^{\cdot+}\right)$ scavenging capacity of Mct and $\mathrm{Mf}$ was measured using the Antioxidant Assay Kit CS0790 (Sigma Chemical Co.), following the manufacturer's instruction. Trolox (6-hydroxy 2,5,7,8-tetramethylchroman2-carboxylic acid) was used as the antioxidant standard. The scavenging activity of was expressed as trolox equivalent ( $\mathrm{mmol} / \mathrm{l}$ of myrtle homogenate).

Concentration of total phenols, flavonoids and anthocyanins Total phenols, flavonoids and anthocyanins were determined on the ME obtained from Mct and Mf. In details, aliquots of myrtle homogenates were centrifuged to remove the solid phase $(10000 \times g$ for $20 \mathrm{~min})$; then, the supernatants were freeze-dried and resuspended (1:1) in $80 \%$ methanol. The ME were purged with nitrogen stream for $30 \mathrm{~min}$, under stirring condition, and centrifuged at $4,600 \times g$ for $20 \mathrm{~min}$. ME were transferred into test tubes, purged with nitrogen stream and stored at ca. $4^{\circ} \mathrm{C}$ before analysis. The concentration of total phenols was determined as described by Slinkard and Singleton [49]. It was expressed as gallic acid equivalent.

The concentration of flavonoids was estimated according to the aluminum chloride colorimetric method of Djeridane et al. [50]. Briefly, $1 \mathrm{ml}$ of $\mathrm{ME}$ was mixed with $1 \mathrm{ml}$ of $2 \% \mathrm{AlCl}_{3}$ methanolic solution. After incubation at room temperature for $15 \mathrm{~min}$, the absorbance was measured at $430 \mathrm{~nm}$. Flavonoid concentration was calculated from a calibration curve obtained with rutin (Sigma Aldrich CO., St. Louis, MO) and expressed as milligrams of rutin equivalent/gram of dry matter (mg $\mathrm{RE} / \mathrm{g} \mathrm{dm}$ ). Data were calculated as the mean of the results obtained in three different experiments.

The concentration of total anthocyanins (TAC) was measured by a pH-differential method proposed by Ozgen et al. [51], using two buffer systems: potassium chloride buffer, pH $1.0(0.0025 \mathrm{M})$ and sodium acetate buffer, pH $4.5(0.4 \mathrm{M})$. Briefly, $1 \mathrm{ml}$ of $\mathrm{ME}$ was mixed with $4 \mathrm{ml}$ of each buffer and read at 510 and $700 \mathrm{~nm}$ against distilled water as a blank. Absorbance was calculated as $\mathrm{A}=\left(\mathrm{A}_{510}-\mathrm{A}_{700}\right) \mathrm{pH} 1.0-\left(\mathrm{A}_{510}-\mathrm{A}_{700}\right)$ $\mathrm{pH}$ 4.5. TAC of samples (mg cyanidin-3glucoside/l of extract) was calculated using the following equation: TAC $(\mathrm{mg} / \mathrm{l})=A \times M W \times D F \times 10^{3} / \varepsilon \times L$ (where $\mathrm{A}$ is the absorbance; MW is the molecular weight of cyanidin-3glucoside, 449.2 Da; DF is the dilution factor; $\varepsilon$ is the cyanidin-3-glucoside molar absorbance, 26,900; $\mathrm{L}$ is the cell path length, $1 \mathrm{~cm}$ ) and expressed on $\mathrm{dm}$.

\section{Extraction and analysis of phenolic compounds}

Extraction of phenolic compounds was carried out following the procedure of Svensson et al. [52], with some modifications. Fifty milliliters of myrtle extracts (Mct and Mf) were mixed with $200 \mathrm{ml}$ of $70 \%$ ( $\mathrm{vol} / \mathrm{vol}$ ) methanol. The mixture was shaken for $1 \mathrm{~h}$ (room temperature) and then centrifuged at $4225 \times g$ for $10 \mathrm{~min}$. The supernatant was collected, and the pellet was subjected to a second extraction cycle. Methanol was evaporated under vacuum at $35^{\circ} \mathrm{C}$ using a Speed-Vac centrifuge at $35^{\circ} \mathrm{C}$ (Thermo Scientific, Waltham, MA). Dry matter was re-dissolved in Milli$\mathrm{Q}$ water $(50 \mathrm{ml})$ and acidified to $\mathrm{pH} 1.5$ with hydrochloric acid. Ethyl acetate (200 ml, Sigma-Aldrich) was added, and the samples were shaken every $10 \mathrm{~min}$ for $30 \mathrm{~min}$ at room temperature. The liquid-liquid extraction was repeated two times, and ethyl acetate evaporated under vacuum at $35^{\circ} \mathrm{C}$. Dry matter was re-dissolved in $10 \mathrm{ml}$ of methanol.

The extract was filtered through a $0.2 \mu \mathrm{m}$-pore-size polytetrafluoroethylene filter (PTFE) (VWR International) and analysed by High Pressure Liquid Chromatography (HPLC) with the method of Curiel et al. [53], with some modifications. An ÄKTA Purifier system (GE Healthcare) equipped with an XTerra reversed-phase $\mathrm{C}_{18}$ column (Waters) was used. Gradient elution was performed at $30^{\circ} \mathrm{C}$ with a flow rate of $0.8 \mathrm{ml} / \mathrm{min}$, using a mobile phase composed of solvent A (water/acetic acid, 98:2) and solvent B (water/acetonitrile/acetic acid, 78:20:2). The solvent B concentration was increased linearly from 0 to $80 \%$ between 0 and $55 \mathrm{~min}$; from 80 to $90 \%$ between 55 and $57 \mathrm{~min}$; 90\% isocratic between 57 and $70 \mathrm{~min}$; from 90 to $95 \%$ between 70 and $80 \mathrm{~min}$; from 95 to $100 \%$ between 80 and $90 \mathrm{~min}$. After, washing and equilibration were carried out. UV detector was set at $280 \mathrm{~nm}$. The identification of compounds was carried out by comparing the retention times and area data of each peak with those of standards from Sigma Aldritch Co.

\section{MTT assay and protective effect on oxidative-induced stress in Balb 3 T3 cells}

Mouse fibroblasts (Balb $3 \mathrm{~T} 3$, clone CCL-163 ${ }^{\mathrm{rm}}$ ) were purchased from ATCC Culture Collection (Middlesex, $\mathrm{UK})$, and were cultured under humidified atmosphere (5\% $\mathrm{CO}_{2}, 37^{\circ} \mathrm{C}$ ), using Dulbecco's Modified Eagle Medium (DMEM), which was supplemented with $10 \%(\mathrm{w} / \mathrm{v})$ calf bovine serum (CBS), $1 \%$ penicillin $(10,000 \mathrm{U} / \mathrm{mL}) /$ streptomycin $(10,000 \mathrm{U} / \mathrm{mL})$ mixture, and $1 \%$ non-essential amino acid solution (NEAA). The culture medium was renewed every two days and after four passages the cultures were used for viability assays.

Cell viability was measured using the MTT (3-(4,5dimethyl-2-yl)-2,5-diphenyltetrazolium bromide) method [54]. The capacity of succinate dehydrogenase to convert 3(4,5-dimethylthiazol-2-yl)-2,5-diphenyltetrazolium bromide 
into visible formazan crystals was assessed. For MTT assay, cells were seeded into 96-well plate (Becton Dickinson France S.A., Meylan Cedex, France) at the density of $5 \times$ $10^{4}$ cells/well and incubated for $24 \mathrm{~h}$.

In order to determine the non-cytotoxic concentration, cells were treated with Mct and Mf and incubated for 24,48 , and $72 \mathrm{~h}$. In particular, the concentrations of freeze-dried Mct and Mf in the reaction mixture were $0.1,1,5,10,50$, and $100 \mathrm{mg} / \mathrm{ml}$. A control in basal medium, without addition of Mct or Mf, was used. After incubation, medium was removed from each well and $100 \mu \mathrm{l}$ of MTT $(0.5 \mathrm{mg} / \mathrm{ml}$ final concentration), dissolved in DMEM, were added and incubated $\left(37^{\circ} \mathrm{C}, 5 \%\right.$ $\mathrm{CO}_{2}$ ) in the dark for $3 \mathrm{~h}$. Finally, $100 \mu \mathrm{l}$ of dimethyl sulphoxide (DMSO) were added to dissolve purple formazan products. The solution was shacked in the dark for $15 \mathrm{~min}$ at room temperature. The absorbance of the solution was read at $570 \mathrm{~nm}$ in a microplate reader (BioTek Instruments Inc., Bad Friedrichshall, Germany).

MTT assay was also used for the determination of the viability of $\mathrm{H}_{2} \mathrm{O}_{2}$-stressed Balb 3 T3 cells [11,13], In this case, cells were incubated with Mct and Mf for $16 \mathrm{~h}$. The concentrations of freeze-dried Mct and Mf in the reaction mixture were 1,5 , and $10 \mathrm{mg} / \mathrm{ml}$. DMEM medium with $2.5 \%$ CBS, $1 \%$ penicillin $(10,000 \mathrm{U} 7 \mathrm{ml}) /$ streptomycin $(10,000 \mathrm{U} / \mathrm{ml})$ and $1 \%$ non-essemtial amino acids solution (NEAA) was used as sunstrate. A negative control, without addition of Mct or Mf, was used. $\alpha$ Tocopherol (250, 500 and $1000 \mu \mathrm{g} / \mathrm{ml}$ ) was used as the positive control. After treatment, medium was removed from each well and, after washing, cells were exposed to $400 \mu \mathrm{M}$ hydrogen peroxide (100 $\mu \mathrm{l} /$ well $)$ for $2 \mathrm{~h}$. Two controls, one without addition of Mct or Mf, and another without hydrogen peroxide treatment, were used.

After the incubation, MTT assay was performed as described above. Data were expressed as the mean percentage of viable cells compared to the control culture, without oxidative stress.

Each experiment was carried out in triplicate.

\section{Intracellular reactive oxygen species (ROS) generation}

Production of reactive oxygen species (ROS) was monitored spectrofluorometrically on mouse fibroblasts Balb 3 T3 using the 2,7'-dichlorofluorescein diacetate (DCFHDA) assay, as described by Tobi et al. [16].

In details, cells were cultivated and treated for $16 \mathrm{~h}$ with 1,5 , and $10 \mathrm{mg} / \mathrm{ml}$ of Mct and Mf as described above. $\mathrm{H}_{2} \mathrm{O}_{2}$-stressed cells were used as control; DMEM (2.5\% CBS) was used as culture medium. After the incubation with Mct and Mf, the medium was removed and washed twice with phosphate buffer saline (PBS). Cells were treated with DCFH-DA dissolved in DMSO (final concentration $100 \mu \mathrm{M}$ ) for $30 \mathrm{~min}$ at $37^{\circ} \mathrm{C}$, in the dark.
Cells were then treated for $2 \mathrm{~h}$ at $37^{\circ} \mathrm{C}$ in the dark with $100 \mu \mathrm{l}$ of pre-warmed DMEM (2,5\% CBS) containing $400 \mu \mathrm{M} \mathrm{H}_{2} \mathrm{O}_{2}$. At the end of the treatment, cells were washed twice, lysed with Cell Lytic $M$ lysis buffer (Sigma Aldrich), added with 1\% protease inhibitor cocktail (Sigma Aldritch) and transferred into a black 96well plate. Fluorescent 2,7'-dichlorofluorescein (DCF) was read fluorometrically using a Fluoroskan Ascent FL Microplate Fluorescence Reader (Thermo Scientific) at excitation and emission wavelengths of 485 and $538 \mathrm{~nm}$, respectively. Each experiment was carried out in triplicate.

\section{Statistical Analysis}

Data were subjected to one-way ANOVA; pair-comparison of treatment means was achieved by Tukey's procedure at $P<0.05$, using the statistical software, Statistica for Windows (Statistica7.0 per Windows). Student's $t$-test was used for MTT assay (GraphPAD 6.0 for Windows).

\section{Competing interests}

The authors declare that they have no competing interests.

\section{Authors' contributions}

JAC and PF performed fermentations, microbiological determination, purification of active compounds anf chemical analyses; DP and BM carried out ex-vivo assays and related experimental procedures; GAF provided myrtle berries from Sardinia and coordinated the chemical analyses; MG was the supervisor and the coordinators of the research units; C.G. Rizzello carried out the experimental design of the work, the purification of bioactive compounds and elaboration of all the data.

\section{Author details}

${ }^{1}$ Dipartimento di Scienze del Suolo, della Pianta e degli Alimenti, University of Bari, Via G. Amendola 165/a Bari 70126, Italy. ${ }^{2}$ Giuliani S.p.A., Milan 20129, Italy. ${ }^{3}$ Dipartimento di Scienze ambientali agrarie e biotecnologie agro-alimentari, Università degli Studi di Sassari, Sassari, Italy.

Received: 27 February 2015 Accepted: 23 April 2015 Published online: 07 May 2015

\section{References}

1. Messaoud C, Laabidi A, Boussaid M. Myrtus communis L. infusions: the effect of infusion time on phytochemical composition, antioxidant, and antimicrobial activities. J Food Sci. 2012;77:C941-7.

2. Messaoud C, Boussaid M. Myrtus communis berry color morphs: a comparative analysis of essential oils, fatty acids, phenolic compounds, and antioxidant activities. Chem Biodiv. 2011;8:300-10.

3. Montoro P, Tuberoso CIG, Perrone A, Piacente S, Cabras P, Pizza C. Characterisation by liquid chromatography-electrospray tandem mass spectrometry of anthocyanins in extracts of Myrtus communis L. berries used for the preparation of myrtle liqueur. J Chromatogr A. 2006;1112:232-40.

4. Le Floc'h E. Contribution a une etude ethnobotanique de la Flore Tunisienne. Tunisia: Imprimerie Officielle de la Republique Tunisienne; 1983. p. 401.

5. Ziyyat A, Legssyer A, Mekhfi H, Dassouli A, Serhrouchni M, Benjelloun W. Phytotherapy of hypertension and diabetes in oriental Morocco. J Ethnopharmacol. 1997;58:45-54.

6. Marchini G, Maccioni S. Liguria in parole povere. La bassa Val di Magra. Sagep Libri Ed., Genova; 1998. p. 159.

7. Aleksic $V$, Knezevic P. Antimicrobial and antioxidative activity of extracts and essential oils of Myrtus communis L. Microbiol Res. 2014;169:240-54.

8. Messaoud C, Zaouali Y, Ben Salah A, Khoudja ML, Boussaid M. Myrtus communis in Tunisia: variability of the essential oil composition in natural populations. Flavour Frag J. 2005;20:577-82. 
9. Wannes AW, Mhamdi B, Sriti J, Ben Jemia M, Ouchikh O, Hamdaoui G, et al. Antioxidant activities of the essential oils and methanol extracts from myrtle (Myrtus communis var. italica L.) leaf, stem and flower. Food Chem Toxicol. 2010:48:1362-70.

10. Tretiakova I, Blaesius D, Maxia L, Wesselborg S, Schulze-Osthoff K, Cinatl Jr J, et al. Myrtucommulone from Myrtus communis induces apoptosis in cancer cells via the mitochondrial pathway involving caspase-9. Apoptosis. 2008;13:119-31.

11. Rizzello CG, Coda R, Sánchez-Macías D, Pinto D, Marzani B, Filanino P, et al. Lactic acid fermentation as a tool to enhance the functional features of Echinacea spp. Microb Cell Fact. 2103;12:44.

12. Pellati F, Benvenuti S, Magro L, Melegari M, Soragni F. Analysis of phenolic compounds and radical scavenging activity of Echinacea spp. J Pharm Biomed Anal. 2004:35:289-301.

13. Coda R, Rizzello CG, Pinto D, Gobbetti M. Selected lactic acid bacteria synthesize antioxidant peptides during sourdough fermentation of cereal flours. Appl Environ Microbiol. 2012;78:1087-96.

14. Qian ZJ, Jung WK, Kim SK. Free radical scavenging activity of a novel antioxidative peptide purified from hydrolysate of bullfrog skin, Rana catesbeiana Shaw. Bioresour Technol. 2008;6:1690-8.

15. Ragaee S, Abdel-Aal ESM, Noaman M. Antioxidant activity and nutrient composition of selected cereals for food use. Food Chem. 2006:98:32-8.

16. Tobi SE, Paul N, McMillan TJ. Glutathione modulates the level of free radicals produced in UVA-irradiated cells. J Photoch Photobio B. 2000;57:102-12

17. Gobbetti M, Di Cagno R, De Angelis M. Functional microorganisms for functional food quality. Crit Rev Food Sci Nutr. 2010;508:716-27.

18. Di Cagno R, Mazzacane F, Rizzello CG, De Angelis M, Giuliani G, Meloni M, et al. Synthesis of $\gamma$-aminobutyric acid (GABA) by Lactobacillus plantarum DSM19463: functional grape must beverage and dermatological applications. Appl Microbiol Biotechnol. 2010;86:731-41.

19. Di Cagno R, Mazzacane F, Rizzello CG, Vincentini O, Silano M, Giuliani G, et al. Synthesis of isoflavone aglycones and equol in soy milks fermented by food-related lactic acid bacteria and their effect on human intestinal Caco-2 cells. J Agric Food Chem. 2010;58:10338-46.

20. Coda R, Rizzello CG, Gobbetti M. Use of sourdough fermentation and pseudo-cereals and leguminous flours for the making of a functional bread enriched of $\gamma$-aminobutyric acid (GABA). Int J Food Microbiol. 2010;137:236-45.

21. Rizzello CG, Nionelli L, Coda R, Gobbetti M. Synthesis of the cancer preventive peptide lunasin by lactic acid bacteria during sourdough fermentation. Nutr Cancer. 2012;64:111-20.

22. Tuberoso CIG, Rosa A, Bifulco E, Melis MP, Atzeri A, Pirisi FM, et al. Chemical composition and antioxidant activities of Myrtus communis $\mathrm{L}$. berries extracts. Food Chem. 2010;123:1242-51.

23. Di Cagno R, Surico RF, Paradiso A, De Angelis M, Salmon JC, Buchin S, et al Effect of autochthonous lactic acid bacteria starters on health-promoting and sensory properties of tomato juices. Int J Food Microbiol. 2009;128:473-83.

24. Di Cagno R, Cardinali G, Minervini G, Antonielli L, Rizzello CG, Ricciuti P, et al. Taxonomic structure of the yeasts and lactic acid bacteria microbiota of pineapple (Ananas comosus L. Merr.) and use of autochthonous starters for minimally processing. Food Microbiol. 2010;27:381-9.

25. Rizzello CG, Nionelli L, Coda R, De Angelis M, Gobbetti M. Effect of sourdough fermentation on stabilisation, and chemical and nutritional characteristics of wheat germ. Food Chem. 2010;119:1079-89.

26. Nionelli L, Curri N, Curiel JA, Di Cagno R, Pontonio E, Cavoski I, et al. Exploitation of Albanian wheat cultivars: characterization of the flours and lactic acid bacteria microbiota, and selection of starters for sourdough fermentation. Food Microbiol. 2014:44:96-107.

27. Wannes WA, Marzouk B. Differences between Myrtle Fruit Parts (Myrtus communis var. italica) in Phenolics and Antioxidant Contents. J Food Biochem. 2013;37:585-94

28. Kuntz S, Wenzel U, Daniel H. Comparative analysis of the effects of flavonoids on proliferation, cytotoxicity, and apoptosis in human colon cancer cell lines. Eur J Nutr. 1999;38:133-42.

29. Aguilera-Carbo A, Augur C, Prado-Barragan LA, Favela-Torres E, Aguilar CN. Microbial production of ellagic acid and biodegradation of ellagitannins. Appl Microbiol Biotechnol. 2008;78:189-99.

30. Rodríguez H, Curiel JA, Landete JM, de Las RB, de Felipe FL, Gómez-Cordovés $C$, et al. Food phenolics and lactic acid bacteria. Int J Food Microbiol. 2009:132:79-90.

31. Osawa R, Kuroiso K, Goto S, Shimizu A. Isolation of tannin-degrading lactobacilli from humans and fermented foods. Appl Environ Microbiol. 2000;66:3093-7.
32. Nishitani Y, Osawa R. A novel colorimetric method to quantify tannase activity of viable bacteria. J Microbiol Methods. 2003;54:281-4.

33. Nishitani Y, Sasaki E, Fujisawa T, Osawa R. Genotypic analysis of lactobacilli with a range of tannase activities isolated from human feces and fermented foods. Syst Appl Microbiol. 2004;27:109-17.

34. Vaquero I, Marcobal A, Muñoz R. Tannase activity by lactic acid bacteria isolated from grape must and wine. Int J Food Microbiol. 2004;96:199-204.

35. Rodríguez H. de las Rivas B, Gómez-Cordovés C, Muñoz R. Degradation of tannic acid by cell-free extracts of Lactobacillus plantarum. Food Chem. 2008:107:664-70.

36. Esteban-Torres M, de las Reverón I, Mancheño JM, Rivas B, Muñoz R, et al. Characterization of a Feruloyl Esterase from Lactobacillus plantarum. Appl Environ Microbiol. 2013;79:5130-6.

37. Barboni T, Cannac M, Massi L, Perez-Ramirez Y, Chiaramonti N. Variability of polyphenol compounds in Myrtus communis L. (Myrtaceae) berries from Corsica. Molecules. 2010;15:7849-60.

38. Dueñas M, Fernández D, Hernández T, Estrella I, Muñoz R. Bioactive phenolic compounds of cowpeas (Vigna sinensis L). Modifications by fermentation with natural microflora and with Lactobacillus plantarum ATCC 14917. J Sci Food Agr. 2005;85:297-304.

39. Bisakowski B, Atwal AS, Gardner N, Champagne CP. Effect of lactic acid fermentation of onions (Allium cepa) on the composition of flavono glucosides. Int J Food Sci Technol. 2007;42:783-9.

40. Filannino P, Azzi L, Cavoski I, Vincentini O, Rizzello CG, Gobbetti M, et al, Exploitation of the health-promoting and sensory properties of organic pomegranate Punica granatum L.) juice through lactic acid fermentation. Int J Food Microbiol. 2013;163:184-92.

41. Manach C, Scalbert A, Morand C, Rémésy C, Jiménez L. Polyphenols: food sources and bioavailability. Am J Clin Nutr. 2004;79:727-47.

42. Di Cagno R, Surico RF, Siragusa S, De Angelis M, Paradiso A, Minervini F, et al. Selection and use of autochthonous mixed starter for lactic acid fermentation of carrots, French beans or marrows. Int J Food Microbiol. 2008;127:220-8.

43. Rizzello CG, Filannino P, Di Cagno R, Calasso M, Gobbetti M. Quorum sensing regulation of constitutive plantaricin by Lactobacillus plantarum strains under vegetables and fruits model system. Appl Environ Microbiol. 2014;80:777-87.

44. Liu G, Sun Y, Guo H. Thermal degradation of anthocyanins and its impact on in vitro antioxidant capacity of downy rose-myrtle juice. J Food Agric Environ. 2013:11:110-4

45. Zwietering $\mathrm{MH}$, Jongeberger I, Roumbouts FM, Van't Riet K. Modelling of bacterial growth curve. Appl Environ Microbiol. 1990;56:1875-81.

46. $\mathrm{Yu}$ L, Perret J, Harris M, Wilson J, Haley S. Antioxidant properties of bran extracts from Akron wheat grown at different locations. J Agric Food Chem. 2003:51:1566-70

47. Osawa T, Namiki M. Natural antioxidants isolated from Eucalyptus leaf waxes. J Agric Food Chem. 1985;33:777-80.

48. Mitsuta H, Yasumoto K, Iwami K. Antioxidative action of indole compounds during the autoxidation of linoleic acid. Eiyo Shohkuryo. 1996;19:210-4.

49. Slinkard K, Singleton VL. Total phenol analysis: automation and comparison with manual methods. Am J Enol Vitic. 1997:28:49-55.

50. Djeridane A, Yousfi M, Nadjemi B, Boutassouna D, Stocker P, Vidal N. Antioxidant activity of some Algerian medicinal plants extracts containing phenolic compounds. Food Chem. 2006:97:654-60.

51. Ozgen M, Reese RN, Tulio Jr AZ, Scheerens JC, Miller AR. Modified 2, 2-Azino-bis-3-ethylbenzothiazoline-6-sulfonic Acid (ABTS) Method to Measure Antioxidant Capacity of Selected Small Fruits and Comparison to Ferric Reducing Antioxidant Power (FRAP) and 2,2'-Diphenyl-1-picrylhydrazyl (DPPH) Methods. J Agric Food Chem. 2006;54:1151-7.

52. Svensson L, Sekwati-Monang B, Lutz DL, Schieber A, Gänzle MG. Phenolic Acids and Flavonoids in Nonfermented and Fermented Red Sorghum (Sorghum bicolor (L.) Moench). J Agric Food Chem. 2010;58:9214-20.

53. Curiel JA, Rodríguez H, Muñoz R. Landete JM, de las Rivas B. Ability of Lactobacillus brevis strains to degrade food phenolic acids Food Chem. 2010;120:225-9.

54. Mosmann T. Toxicity determined in vitro by morphological alterations and neutral red absorption. J Immunol Meth. 1983;65:56-63. 